\title{
Sensitive Detection of Methyl Parathion in Human Urine Using Carboxyl-Group Functionalized Carbon Nanotubes/Carbon Paper-Based Electrochemical Sensor
}

\author{
Cuiling Wang ${ }^{1,2,3, *}$, Jiateng Zhong ${ }^{2}$, Jianhe $\mathrm{Hu}^{1, *}$, Gaiping Zhang ${ }^{3, *}$ \\ ${ }^{1}$ College of Animal Science and Veterinary Medicine, Henan Institute of Science and Technology, \\ Xinxiang 453003, China \\ ${ }^{2}$ School of Basic Medical Science, Xinxinag Medical University, Xinxiang 450003, China \\ ${ }^{3}$ College of Animal Science and Veterinary Medicine, Henan Agricultural University, Zhengzhou \\ 450000, China \\ *E-mail: Wangc10229@163.com ; Jianhehu@126.com ; zhanggaiping2003@163.com
}

doi: $10.20964 / 2021.01 .03$

Received: 2 September 2020 / Accepted: 26 October 2020 / Published: 30 November 2020

\begin{abstract}
The excessive use of methyl parathion (MP) has a serious negative impact on human health and ecological environment. In order to monitor the MP residual, a highly sensitive electrochemical sensor was fabricated with the carboxyl-group functionalized carbon nanotubes modified carbon paper electrode (COOH-CNT/CPE) for the determination of MP. The carboxyl-group functionalized carbon nanotubes (COOH-CNT) possessed high electrical conductivity, large specific surface area, and good electrochemical catalytic performance. The existence of carboxyl groups contributed to the uniform dispersion of carbon nanotubes in liquid solution. Moreover, carbon paper electrode (CPE) presented low cost and easy operation. Research results showed good synergistic interaction of the fabricated $\mathrm{COOH}-\mathrm{CNT} / \mathrm{CPE}$ sensor. Under the optimal conditions, the fabricated $\mathrm{COOH}-\mathrm{CNT} / \mathrm{CPE}$ sensor exhibited good determination performance of MP with a low detection limit of $27 \mathrm{nM}$ in a great linear MP concentration of 0.06-4 $\mu \mathrm{M}$ and 4-30 $\mu \mathrm{M}$. Moreover, the COOH-CNT/CPE sensor could show good practicability for the determination of MP in human urine. This work is meaningful to the development of the simple, low-cost, and sensitive MP sensor.
\end{abstract}

Keywords: COOH-CNT/CPE sensor; Synergetic interaction; Electrochemical determination; Methyl parathion; Human Urine

\section{FULL TEXT}

(C) 2021 The Authors. Published by ESG (www.electrochemsci.org). This article is an open access article distributed under the terms and conditions of the Creative Commons Attribution license (http://creativecommons.org/licenses/by/4.0/). 